\title{
Establishing empirical relationship to predict the chaff cutting phenomenon energized by human powered flywheel motor (hpfm).
}

\author{
P.B.Khope ${ }^{1}$, J.P.Modak ${ }^{2}$ \\ ${ }^{1}$ Research Scholar \& Assistant Professor,Department of Mechanical Engineering,Priyadarshini College of \\ Engineering, Nagpur, Maharashtra, INDIA. \\ ${ }^{2}$ Emeritus Professor (AICTE) \& Dean $(R \& D)$, Department of Mechanical Engineering,Priyadarshini College \\ of Engineering, Nagpur, Maharashtra, INDIA.
}

\begin{abstract}
In India animal husbandry is an integral part of the rural economy. Almost every rural family keeps at least a cow or buffalo for meeting milk requirement and to earn some money for daily expenses. The milk production is greatly affected by feeding to the cattle. However most of cattle feeding are provided in the form of whole crop. It may leads to wastage of feeding. It was noted that there is always feeding fodder scarcity in summer. In such situation the whole crop is to be cut into small pieces so that fodder can be used effectively.

Presently fodder cutting machines are electric driven as well as hand operated. But today there is huge shortage of electricity almost every parts of India. To overcome uncertainly of electricity, we can replace electrically driven motor by human powered flywheel motor. The chaff cutter energized by human powered flywheel motor is suitable for marginal farmer who have 2-3 cattle. The experimentation carried out for establishing empirical model for identified variables affecting cutting of crop resides.
\end{abstract}

\section{Introduction:}

Animal feeding is very important aspect of livestock husbandry. It is very necessary to have effective utilization of available feed sources. The cutting of crop resides into small pieces then feeding to the cattle, increases the consumption and palatability of feed, hence reducing the wastage.

Modak and his associates [01to11] had developed Human powered process machines, which could energize process units needing 3 to $6 \mathrm{HP}$. These units had intermittent power requirement. In the present work human powered flywheel motor chaff cutting process has been studied. The power that can be developed by an average healthy athlete is $75 \mathrm{~W}$ maximum [3]. A person can generate more or same amount for longer if they paddle at certain rate. Owing these limitations of human capabilities the proposed machine consists of a flywheel for storing the energy.

The system is made up of three subsystems

(i) Energy unit comprising of a flywheel of size 01 meter rim diameter, $10 \mathrm{~cm}$ rim width speed amplification gear pair, and traditional bicycle.

(ii) Spiral Jaw clutch and torque amplification gear pair.

(iii) Process unit.

\section{Human Powered Chaff Cutter}

The schematic arrangement of a forge cutter is shown in fig-1. The operator drives the bicycle, thereby gives the motion to the flywheel via the chain drive and speed amplification gear pair. The chain drive is used for first stage transmission. This drive is irreversible, achieved by bicycle chain and free wheel. A free wheel prevents the back flow of energy from flywheel to pedals. Thus human energy is transferred to the flywheel.

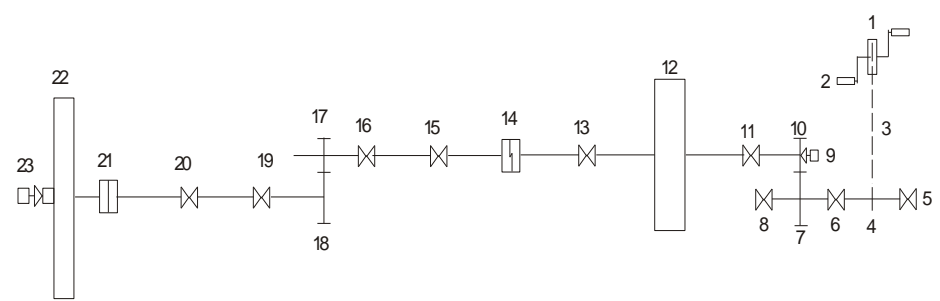

Fig. 1 Schematic of Human Powered Flywheel Motor. 
1-Chain Sprocket 2-Pedal 3-Chain 4-Freewheel 5,6-Bearings for bicycle side 7-Gear-I 8-Bearing 9Tachogenerator for flywheel shaft 10-Pinion-I 11-Bearing for flywheel shaft 12-Flywheel 13-Bearing for flywheel 14-Two jaw clutch 15,15-Bearing of intermediate shaft 17-Pinion II 18-Gear II 19,20-Bearing for process unit shaft21-Coupling 22-Chaff Cutter blade 23-Tachogenerator for chaff Cutter shaft

A 30-35 aged operator with slim stature speeds up the flywheel to 600-700 rpm. in a minute. After attaining the required speed of the flywheel paddling is stopped. The process unit i.e. cutter is connected to the flywheel shaft by the clutch via a torque implications gear pair. The gear pair is selected as per test envelope. The energy stored in the flywheel is supplied at the required rate to the cutter.

There is an arrangement for automatic feeding of fodder by means of feed gears. The feeding rate is depends on speed of feed gear. The speed of cutter shaft decides the speed of feed gears. Also the manual feeding is possible. Fig. 2 shows the drawing of experimental set-up.

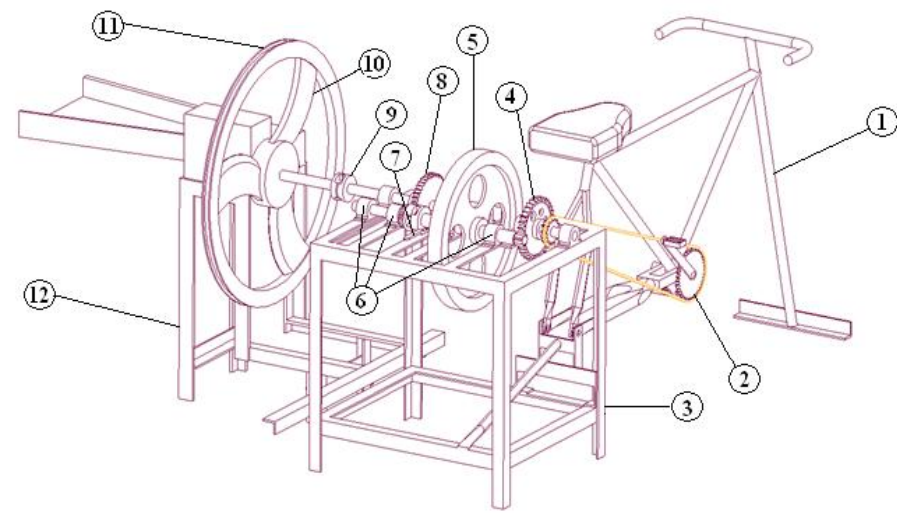

1. Cycle Stand 2.Freewheel 3.Frame 4.Speed Rising Gear Pair 5. Flywheel 6. Bearing

7. Clutch 8.Torque amplification gear pair 9.Coupling 10.Cutter shaft 11.Chopper blade 12. Cutter Frame Figure2. Drawing of the experimental set-up.

\section{Design Of Experimentation}

The forage cutting operation energized by human powered flywheel motor is complex phenomena. In this system, after the clutch engagement there is an instantaneous momentum transfer through clutch to the process unit, thereby suddenly imparting severe acceleration to the process unit. Input shaft and process unit is subjected to deceleration depending on process resistance.

A process resistance as regards the application type is some exponential function of speed thereby subjecting flywheel, clutch and process unit to severe condition of transient phases of dynamics of the operation of this novel machine system.

Hence, it is highly improbable to formulate logic based models simulating various phases of energy transfer such as: (i) energy transfer phenomenon i.e. energy release from human body to flywheel (needs 60 seconds) however energy release phenomena from the human body being highly nonlinear [03]. (ii) Upon clutch engagement instantaneous $(0-10 \mathrm{~ms})$ heavy momentum exchange through double jaw spiral clutch to process unit operating on load, inducing severe random vibrations in the clutch and (iii) energy transfer from flywheel through clutch, torque amplification gear pair and process unit.

Alternatively, therefore we left with adopting the approach of "Theory of Engineering Experimentation [15]. The response data is collected.

\section{Methodology Of Experimentation}

a) Identification of Independent, dependent, and extraneous variables affecting the cutting process.

b) Dimensional Analysis :

Empirical relationship among the dependent and independent variables was developed on the basic of dimensional analysis. Dimensional analysis offer a method for reducing complex physical problem to the simplest (that is most economical) form prior to obtaining the quantitative solution.

The empirical relationship between dependent variables and independent variables was developed as follows:

i) Resistive torque : $\mathrm{TC}$

$\mathrm{T}_{\mathrm{c}}=\mathrm{f}\left(\mathrm{D}, \mathrm{d}, \mathrm{g}, \mathrm{n}, \mathrm{E}, \mathrm{W}_{\mathrm{b}} \mathrm{t}_{\mathrm{b}}, \alpha, \mathrm{I}, \omega, \mathrm{G}, \mathrm{t}_{\mathrm{c}}, \mathrm{e}\right)$

ii) No. of cuts : $\mathrm{Cp}$

$\mathrm{Cp}=\mathrm{f}\left(\mathrm{D}, \mathrm{d}, \mathrm{g}, \mathrm{n}, \mathrm{E}, \mathrm{W}_{\mathrm{b}} \mathrm{t}_{\mathrm{b}}, \alpha, \mathrm{I}, \omega, \mathrm{G}, \mathrm{t}_{\mathrm{c}}, \mathrm{e}\right)$

iii) Time required for cutting: tp

$$
\mathrm{t}_{\mathrm{p}}=\mathrm{f}\left(\mathrm{D}, \mathrm{d}, \mathrm{g}, \mathrm{n}, \mathrm{E}, \mathrm{W}_{\mathrm{b}} \mathrm{t}_{\mathrm{b}}, \alpha, \mathrm{I}, \omega, \mathrm{G}, \mathrm{t}_{\mathrm{c}}, \mathrm{e}\right)
$$


Where,

$\mathrm{d}=$ Hub Diameter of blade

$\mathrm{t}_{\mathrm{b}}=$ Thickness of cutting blade

$\mathrm{W}_{\mathrm{b}}=$ Width of cutting blade

$\mathrm{D}=$ Tip diameter of blade

$\mathrm{g}=$ Acceleration due to gravity

$\mathrm{E}=$ Young's modulus of elasticity of cutting blade

I = Moment of inertia of flywheel

$\mathrm{G}=$ Gear ratio

$\alpha=$ Cutting blade angle

$\mathrm{n}=$ Number of blades

$\omega=$ Angular velocity

$\mathrm{C}_{\mathrm{p}}=$ Number of cuts during cutting

$\mathrm{e}=$ Kinetic energy of flywheel

$\mathrm{T}_{\mathrm{c}}=$ Instantaneous torque on cutting blade

$\mathrm{t}_{\mathrm{p}}=$ Process time for cutting

\subsection{Dimensional Consideration:}

Next, list the dimensions of the dependent variables and the independent variables. All these variables expressed in terms of three primary dimensions i.e. MLT. The Dimensional matrix is given in Tables 1.

Table1: Dimensional matrix

\begin{tabular}{|c|c|c|c|c|c|c|c|c|c|c|c|c|c|c|c|}
\hline & $\mathrm{W}_{\mathrm{b}}$ & $\mathrm{t}_{\mathrm{b}}$ & $\mathrm{D}$ & $\mathrm{g}$ & $\mathrm{I}$ & $\mathrm{E}$ & $\alpha$ & $\mathrm{n}$ & $\omega$ & $\mathrm{t}_{\mathrm{c}}$ & $\mathrm{e}$ & $\mathrm{G}$ & $\mathrm{T}_{\mathrm{c}}$ & $\mathrm{C}_{\mathrm{p}}$ & $\mathrm{t}_{\mathrm{p}}$ \\
\hline $\mathrm{M}$ & 0 & 0 & 0 & 0 & 0 & 1 & 0 & 0 & 0 & 0 & 1 & 0 & 1 & 0 & 0 \\
\hline $\mathrm{L}$ & 1 & 1 & 1 & 1 & 1 & -2 & 0 & 0 & 0 & 0 & 2 & 0 & 2 & 0 & 0 \\
\hline $\mathrm{T}$ & 0 & 0 & 0 & -2 & -2 & -1 & 0 & 0 & -1 & 1 & -2 & 0 & -2 & 0 & 1 \\
\hline
\end{tabular}

When the dimension matrix is solved the dimensionless $\pi$ terms are obtained. The dimension less $\pi$ terms are combined and arranged depending on the nature of basic physical quantities and listed in table 2 . Thus each dependent $\pi$ terms are assumed be the function of the available independent $\pi$ terms.

$$
\begin{gathered}
\frac{D}{g I} T_{c}=\mathrm{f}\left(\pi_{1}, \pi_{2}, \pi_{3}, \pi_{4}, \pi_{5}, \pi_{6}, \pi_{7}, \pi_{8}\right) \\
\mathrm{Cp}=\mathrm{f}\left(\pi_{1}, \pi_{2}, \pi_{3}, \pi_{4}, \pi_{5}, \pi_{6}, \pi_{7}, \pi_{8}\right) \\
\sqrt{\frac{g}{D}} t_{p}={ }_{\mathrm{f}}\left(\pi_{1}, \pi_{2}, \pi_{3}, \pi_{4}, \pi_{5}, \pi_{6}, \pi_{7}, \pi_{8}\right)-
\end{gathered}
$$

Table 2. Dimensionless $\pi$ terms

\begin{tabular}{|c|c|l|}
\hline $\begin{array}{c}\text { Sr. } \\
\text { No. }\end{array}$ & $\begin{array}{c}\text { Independent dimensionless ratio } \\
\text { or } \pi \text { terms }\end{array}$ & Nature of basic physical quantities \\
\hline 1 & $\pi_{1}=\frac{d w_{b} t_{b}}{D^{3}}$ & Geometric Variables \\
\hline 2 & $\pi_{2}=\frac{D^{4}}{g I} E$ & Material of blade \\
\hline 3 & $\pi_{3}=\sqrt{\frac{D}{g}} \omega_{c}$ & Instantaneous Terminal velocity of cutter \\
\hline 4 & $\pi_{4}=G$ & Gear Ratio \\
\hline 5 & $\pi_{5}=\alpha$ & Cutting blade angle \\
\hline 6 & $\pi_{6}=\mathrm{n}$ & No. of cutting blade \\
\hline 7 & $\pi_{7}=\sqrt{\frac{g}{D}} t_{c}$ & Cutting time \\
\hline 8 & $\pi_{8}=\frac{D}{2 g} \omega_{f}^{2}$ & Terminal speed of flywheel \\
\hline 9 & $\pi_{D 1}=\frac{D}{g I} T_{c}$ & Resistive torque \\
\hline 10 & $\pi_{D 2}=C_{p}$ & No. of cuts by cutter \\
\hline 11 & $\pi_{D 3}=\sqrt{\frac{g}{D}} t_{p}$ & Process time \\
\hline
\end{tabular}

\section{Experimentation Design:}

\subsection{Test Envelope and Test point planning:-}

To carry out the experimentation it is necessary to decide the range of parameters selected. In the present work sixteen variables has been selected for experimentation. Depending upon adjustment possibility of experimental set up, influence of variables, the feasible range of parameters has been decided. Table 2 gives the complete Test planning. 
Table No. 2 - Test planning

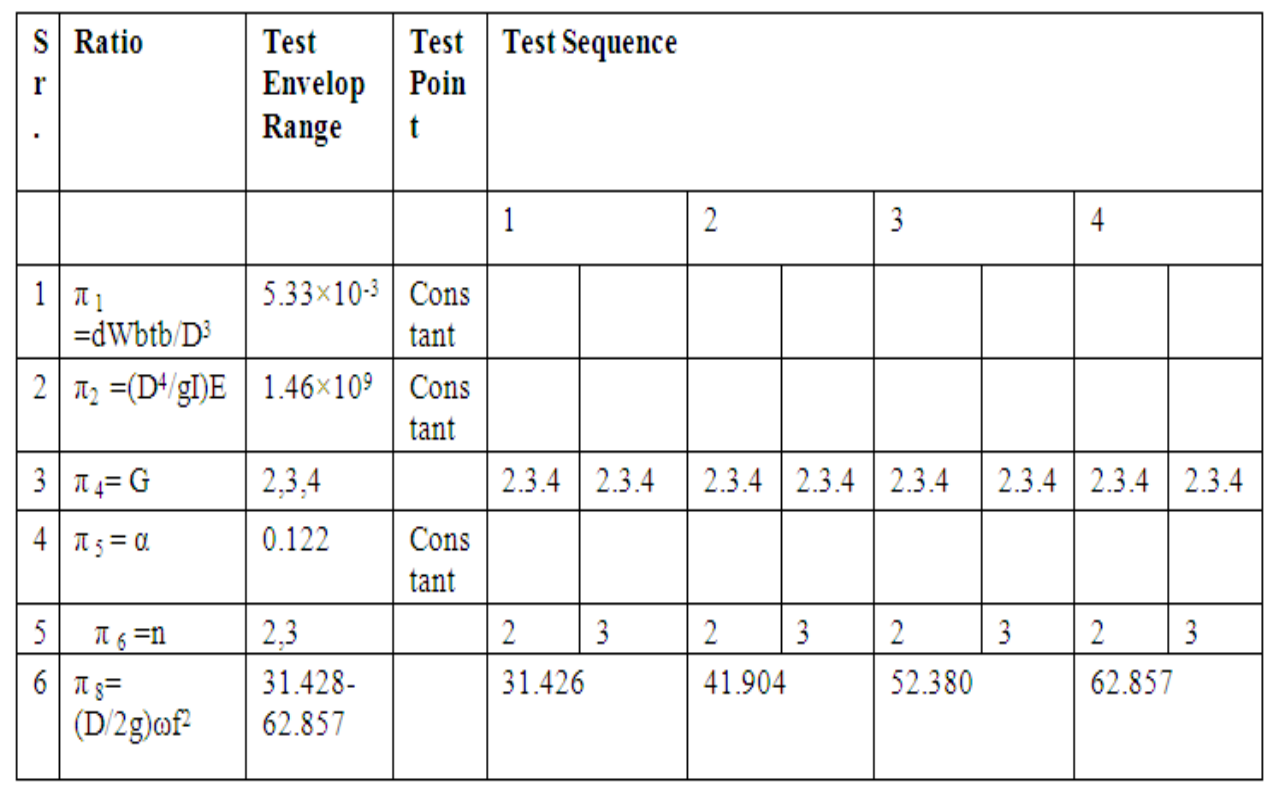

Note: $\pi_{3}=$ It can't be predefined as the angular velocity change during experimentation. The reading will be noted during

Experimentation.

$\pi_{7}=$ the specific time instant during cutting is a dynamic term. It is noted during experimentation.

\section{Instrumentation And Measurement}

1. Linear Measurement: For linear measurement digital calipers and micrometers were used. The blade angle is measures by bevel protector.

2. Angular Velocity: Angular velocity of cutter shaft and flywheel shaft is to be measured. The slotted optocouplers were mounted on the shaft. These sensors measure the angular velocity with real time clock. This angular velocity is recorded and stored via micro controller 89C51 RD2 which is connected to personal computer through USB port.

3. Variation in torque: The variation of torque on cutter shaft will be evaluated on the basis of speed plots of cutter speed verses time.

4. Number of cuts: It was decided to evaluate number of cuts on the basis of speed of cutter obtained during experimentation. No. of cuts $=$ No. of blade X no, of revolution.

5. Process time: It can be evaluated on the basic of $\pi$ terms obtained from dimensional analysis.

$$
\text { Process time }=\pi_{7}=\sqrt{\frac{g}{D}} t_{c}
$$

Where tc $=$ Time required for cutting between two fixed time interval.

\section{Model Development}

The prediction equation is established by allowing one $\pi$ term to vary at a time while keeping other $\pi$ terms constant and observing the resulting changes in the function of the cutter.

An approximate generalized empirical prediction model chaff cutter energized by Human powered flywheel motor has been established. There are three dependant variable i.e. resistive torque $\left(\pi_{\mathrm{D} 1}\right)$ number of cats $\left(\pi_{\mathrm{D} 2}\right)$ and process time $\left(\pi_{\mathrm{D} 3}\right)$. Accordingly three models were developed.

1. Model for Resistive torque : $\pi$ D1
$\pi_{\mathrm{D} 1}=-0.03165\left(\pi_{1}\right)^{-0.005}$
$\left(\pi_{2}\right)^{0.00833}\left(\pi_{3}\right)^{-0.04258}$
$\left(\pi_{4}\right)^{-0.00266}\left(\pi_{5}\right)^{0.06515}$
$\left(\pi_{6}\right)^{-0.04162}\left(\pi_{7}\right)^{0.02176}\left(\pi_{8}\right)^{-0.00171}$

Number of cuts by cutter: $\pi_{\mathrm{D} 2}$

$\pi_{\mathrm{D} 2}=3.94432\left(\pi_{1}\right)^{0.00126}\left(\pi_{2}\right)^{0.00276}\left(\pi_{3}\right)^{0.05510}\left(\pi_{4}\right)^{0.02564}\left(\pi_{5}\right)^{0.02309}\left(\pi_{6}\right)^{0.00458}\left(\pi_{7}\right)^{-0.01041}\left(\pi_{8}\right)^{0.00025}$

2. Process time : $\pi_{\mathrm{D} 3}$

$\pi_{\mathrm{D} 3}=24.4279\left(\pi_{1}\right)^{0.00173}\left(\pi_{2}\right)^{0.00066}\left(\pi_{3}\right)^{-.000172}\left(\pi_{4}\right)^{0.00529}\left(\pi_{5}\right)^{0.00925}\left(\pi_{6}\right)^{-0.02496}\left(\pi_{7}\right)^{-0.02270}\left(\pi_{8}\right)^{0.00368}$ 


\section{Result And Discussion}

Effect of Individual independent variable on

(A) Resistive Torque :

The geometric variable i.e hub diameter width of blade and thickness of cutting blade have a inverse relationship.

If the hub diameter, width of blade and thickness of the blade increases the resistive torque decreases where as the tip diameters of the blade increase the resistive torque increases.

Resistive torque increases with the increase in young modulus of elasticity of blade.

The terminal velocity increases the resistive decreases.

The gear ratio increases the torque decreases.

Resistive torque increases with increase in blade angle.

The increase in kinetic energy the Resistive torque decreases.

\section{B) On number of cuts by cutter:}

There is linear relationship of number of cuts by cutter with geometric variables, material of blade, Terminal velocity of cutter, gear ratio, cutting blade angle., No. of blades and Terminal speed of flywheel.

\section{C) On process time:}

The process time increase due to increment in geometric variables, gear ratio, cutting blade angle.

The process time decreases with increase of Young modules of blade, velocity of cutter, Number of blades and terminal speed of flywheel.

\section{Conclusion}

An Empirical relationship for predicating the chaff cutting phenomena energized by human powered flywheel motor was established using dimensional analysis. The developed relationship describes Resistive torque, number of cuts and process time. The experimentation shows the effect of each independent variable on dependent variables. The level of exponent in the empirical equations show the significance of effect on variable and it is logically appropriate.

\section{Acknowledgements}

The full financial support of Rajiv Gandhi Science \& Technology Commission, Government of Maharashtra to the successful completion of this research is hereby greatly acknowledged.

\section{References}

[1] Modak, J. P. et all, "Manufacturing of Lime-fly ash-sand bricks using manually driven brick making machine", a project sponsored by Maharashtra Housing \& Area Development Authority, (MHADA), Bombay, India.

[2] Modak, J. P. and Bapat, A. R., "Formulation of Generalized Experimental Model for a Manually Driven Flywheel Motor and its Optimization", Applied Ergonomics, U.K., Vol. 25, No. 2, pp 119-122, 1994.

[3] Modak J. P. and Bapat A. R. "Various efficiency of a Human Power Flywheel motor" Human Power, USA International Human Power Vehicle Association No. 54, pp 21-23 Spring 2003.

[4] Modak J. P. "Design and development of manually energized process machines having relevance to village / agriculture and other productive operations" Human Power, USA International Human Power Vehicle Association no 58 pp 16-22, fall 2004

[5] Deshpande S. B., Modak, J. P.and Tarnekar S. B., "Confirming Application of human powered flywheel motor as an energy source for rural generation of electrical energy for rural applications, and computer aided analysis of battery charging process.", Human Power, USA International Human Power Vehicle Association no 58 pp 10-16Summer 2009

[6] Askhedkar R. D. and Modak J. P. "Hypothesis for the Extrusion of Lime-Fly-ash-Sand Bricks Using Manually Driven Brick Making Machine" Building Research \& Information U.K. Vol. 22,N1, pp 47-54 1994.

[7] Sohoni V.V., H. P. Aware and Modak J. P "Manually Powered Manu-facture of Keyed Bricks" Building Research \& Information, U.K. Vol. 25, N6, Pp 354-364, 1997

[8] Modak, J. P. and Bapat, A. R, "Manually driven flywheel motor operates wood turning process" Contemporary Ergonomics, Proc. Ergonomics Society Annual Convention 13-16 April, Edinburgh, Scotland, pp 352-357, 1993

[9] Modak, J. P. and Katpatal A.A., "Design of Manually Energized Centrifugal Drum Type Algae Formation Unit" Proceedings International AMSE Conference on System, Analysis, Control and Design, Layon (France), Vol. 3, 4-6 July 1994, pp $227-232$.

[10] Dhale A. and Modak, J. P., "Formulation of the approximate generalized data based model for oilseed presser using human powered flywheel motor as an energy source" International Journal of Agricultural Engineering,

[11] Modak, J. P., et all, "Influence of development and human powered process machine and its impact on energy management of rural and interior sector", Proceeding of National Conference on Energy Management in Changing Business Scenario, (EMCBS 2005), 8-9 October 2005, BITS Pilani.

[15] H. Schenk Jr., "Theories of Engineering Experimentation”, McGraw Hill Book Company, New York, 1961. 